\title{
PERSISTÊNCIA DO HERBICIDA SULFENTRAZONE EM SOLO CULTIVADO COM CANA-DE-AÇÚCAR $\left({ }^{1}\right)$
}

\author{
FLÁVIO MARTINS GARCIA BLANCO $\left({ }^{2 *}\right)$; EDIVALDO DOMINGUES VELINI $\left({ }^{3}\right)$; \\ ANTONIO BATISTA FILHO $\left({ }^{2}\right)$
}

\begin{abstract}
RESUMO
O objetivo do trabalho foi determinar o comportamento do herbicida sulfentrazone em solo francoargilo-arenoso cultivado com cana-de-açúcar. O delineamento experimental foi o de blocos ao acaso com cinco repetições e três tratamentos de sulfentrazone $\left(0,0 ; 0,6\right.$ e 1,2 $\left.\mathrm{kg} \mathrm{ha}^{-1}\right)$, aplicado como pré-emergente. Foram coletadas periodicamente amostras de solo $(0-10 \mathrm{~cm})$, em 23 épocas entre 0 e 704 dias após o tratamento (DAT). O comportamento do herbicida sulfentrazone foi avaliado por bioensaios usando a beterraba como planta-teste, sendo determinada que para a menor dose $\left(0,6 \mathrm{~kg} \mathrm{ha}^{-1}\right)$, o herbicida persistiu até 601 DAT. Para a dose de 1,2 $\mathrm{kg} \mathrm{ha}^{-1}$, até o fim do ensaio aos 704 DAT, o herbicida ainda persistia. A persistência do herbicida sulfentrazone no solo é longa e proporcional à dose aplicada.
\end{abstract}

Palavras-chave: resíduo, bioensaios, persistência, Saccharum $s p$

\section{ABSTRACT \\ PERSISTENCE OF THE HERBICIDA SULFENTRAZONE IN SOIL CULTIVATED WITH SUGARCANE}

The objective here was to determine the behavior of sulfentrazone in sandy clay soil cultivated with sugar cane. The experimental design was randomized blocks with five replications and three treatments of sulfentrazone $\left(0.0,0.6\right.$ and $\left.1.2 \mathrm{~kg} \mathrm{ha}^{-1}\right)$, applied as pre-emergent. Samples of soil $(0-10 \mathrm{~cm})$, were regularly collected at 23 times between 0 and 704 days after treatment (DAT). The behavior of sulfentrazone was evaluated by bioassays using sugar beet as test plant, and analysis indicated that for the lower dose $\left(0.6 \mathrm{~kg} \mathrm{ha}^{-1}\right)$, the herbicide persisted until $601 \mathrm{DAT}$. At the end of the test, 704 DAT, the herbicide still persisted for the dose of $1.2 \mathrm{~kg} \mathrm{ha}^{-1}$. The persistence of sulfentrazone in soil is long and proportional to applied dose.

Key words: residue, bioassay, persistence, Saccharum sp.

$\left({ }^{1}\right)$ Parte da Tese de doutorado do primeiro autor. Recebido para publicação em13 de janeiro de 2007 e aceito em 15 de novembro de 2009.

$\left({ }^{2}\right)$ Instituto Biológico - Centro Experimental do Instituto Biológico, Rod. Heitor Penteado, Km 3 Caixa Postal 70, 13001-970 Campinas (SP). E.mail: garciablanco@biologico.sp.gov.br $\left(^{*}\right)$ Autor correspondente. batistaf@biologico.sp.gov.br

$\left({ }^{3}\right)$ Faculdade de Ciências Agronômicas - UNESP/Campus de Botucatu, Fazenda Experimental Lageado, Caixa Postal 237, 18603-970 Botucatu (SP). E-mail: velini@fca.unesp.br 


\section{INTRODUÇÃO}

Para cana-de-açúcar, das 33 moléculas de herbicidas registradas no Brasil, descritas pela Agência Nacional de Vigilância Sanitária - ANVISA, em sua maioria (23), são de ação residual, aplicados como pré-emergentes. Muitos apresentam longo poder residual, principalmente aqueles indicados para a cultura plantada no final da época das chuvas.

Desta forma, a cana-de-açúcar deve ser a cultura que apresenta maior potencial de risco de ocorrência de problemas relacionados à permanência de moléculas de herbicidas no solo, por um tempo além do desejável, passível de causar contaminação ambiental e toxicidade para culturas sensíveis utilizadas em sucessão à cana-de-açúcar.

De modo particular, quando a persistência dos herbicidas no solo é determinada por métodos biológicos, utilizando como indicador uma planta sensível a um determinado herbicida (planta-teste), é possível avaliar o tempo do resíduo com bioatividade, podendo assim, além de avaliar seu impacto ambiental, estimar o tempo em que pode permanecer no solo, e afetar culturas sensíveis, em um sistema de sucessão ou rotação de culturas.

Sulfentrazone é um herbicida registrado no Brasil para as culturas de soja, cana-de-açúcar, café e citrus. Pertence ao grupo das aril-triazolinonas, solubilidade de $780 \mathrm{mg} \mathrm{L}^{-1}$ (pH 7), pressão de vapor $110^{-9} \mathrm{mmHg}\left(25^{\circ} \mathrm{C}\right)$, constante de dissociação $(\mathrm{pK})$ 6,56 e coeficiente de partição $\left(K_{\text {ow }}{ }_{\mathrm{pH7}}\right)$ 9,8 (HEss, 1993; Rodrigues e Almeida, 2005; Tomlin, 1994).

REDDY e LOCKE (1998), investigando a sorção no solo do sulfentrazone em duas texturas de solo (média e pesada), e em dois sistemas (convencional e plantio direto), observaram que, independentemente do manejo, a taxa de sorção foi maior no solo argiloso e neste, a dessorção ocorreu de forma bem lenta. Segundo Grey et al. (1997), os processos de sorção/ dessorção do sulfentrazone aos colóides são muito influenciados pelo índice $\mathrm{pH}$. A sorção diminui em resposta a um aumento deste índice, particularmente quando este é acima do pK do herbicida $(6,56)$, condição em que predomina a forma ionizada; abaixo deste valor há o aumento da forma molecular e da sorção.

Blanco e Velini (2005), utilizando a beterraba como planta-teste crescendo dentro de um fitotron, determinaram a persistência do sulfentrazone aplicado em janeiro na cultura da soja, nas doses de $0,6 \mathrm{~kg} \mathrm{ha}^{-1}$ em 376 dias, sendo fitotóxico para as culturas sucedâneas de aveia branca e milheto e não prejudicando as do feijão, girassol e trigo.
Rossi et al. (2003), utilizando bioensaios, avaliaram a lixiviação do sulfentrazone $\left(0,86 \mathrm{~kg}^{-} \mathrm{ha}^{-}\right.$ ${ }^{1}$ ), em dois tipos de solo (Nitossolo Vermelho e Neossolo Quartzarênico), em colunas de PVC; 0,10 e 0,50 m (diâmetro e comprimento), utilizando o sorgo (Sorghum bicolor), sob diferentes regimes pluviométricos durante 15 dias. Determinaram que sob precipitação pluvial de $90 \mathrm{~mm}$, o herbicida foi detectado até 7,5 e $12,5 \mathrm{~cm}$ de profundidade, respectivamente em solo Nitossolo Vermelho e Neossolo Quartzarênico.

Estes dados são coerentes com Vivian et al. (2006) que, investigando o comportamento do sulfentrazone até $20 \mathrm{~cm}$ de profundidade, aplicado na dose de $0,9 \mathrm{~kg} \mathrm{ha}^{-1}$ na cultura da cana-de-açúcar, determinaram com bioensaios, utilizando o sorgo como planta- teste, que a lixiviação do herbicida é significativa somente na camada de $0-10 \mathrm{~cm}$ do solo e sua persistência em 467 DAT. Porém, quando houve reaplicação do herbicida na cana-soca, o fim da persistência não pode ser determinado, pois até a última avaliação (640 DAT), o herbicida ainda persistia no solo. Neste mesmo trabalho, foi determinada a relação de sorção (RA) em 3,6, indicando que este herbicida, quando sorvido aos colóides, tem tendência de lenta disponibilização para a solução.

O objetivo do trabalho, aqui apresentado, foi determinar o comportamento do herbicida sulfentrazone, aplicado na cultura de cana-de-açúcar nas doses de 0,6 e 1,2 $\mathrm{kg} \mathrm{ha}^{-1}$, em Podzol vermelho amarelo, localizado na região de Campinas (SP).

\section{MATERIAL E MÉTODOS}

O experimento foi desenvolvido em Campinas (SP), a $22^{\circ} 54^{\prime}$ latitude Sul, $47^{\circ} 04^{\prime}$ longitude Oeste e $693 \mathrm{~m}$ de altitude, em podzol vermelho-amarelo eutrófico, topografia plana, em área sem histórico de aplicação de herbicidas por quatro anos, com as seguintes características $(0-10 \mathrm{~cm})$ - químicas: $\mathrm{pH}$ 6,4; matéria orgânica $11 \mathrm{~g} \mathrm{dm}^{-3} ; \mathrm{P}$ em resina $8 \mathrm{mg} \mathrm{dm}^{-3} ; \mathrm{K} 3,9 \mathrm{nnol}_{\mathrm{C}} \mathrm{dm}^{-3}$; Ca $67 \mathrm{nnol}_{\mathrm{C}} \mathrm{dm}^{-3} ; \mathrm{Mg} 30$ $\mathrm{nnol}_{\mathrm{c}} \mathrm{dm}^{-3} ; \mathrm{H}+\mathrm{Al} 20 \mathrm{nnol}_{\mathrm{c}} \mathrm{dm}^{-3}$; CTC 120,9 $\mathrm{nnol}_{\mathrm{C}} \mathrm{dm}^{-3}$; SB 100,9 $\mathrm{nnol}_{\mathrm{c}} \mathrm{dm}^{-3} ; \mathrm{V} \mathrm{83,4} \%$ e físicas: Argila $227 \mathrm{~g} \mathrm{~kg}^{-1}$; Silte $129 \mathrm{~g} \mathrm{~kg}^{-1}$; Areia $642 \mathrm{~g} \mathrm{~kg}^{-1}$; Classe textural franco-argilo-arenosa.

A cultivar de cana-de-açúcar SP8018160, na quantidade de $10 \mathrm{t} \mathrm{ha}^{-1}$ (toletes), foi plantada em solo preparado por meio de uma aração e duas gradagens com adubação de $500 \mathrm{~kg} \mathrm{ha}^{-1}$ da fórmula 25-25-25, em 29 de março de 2000. 
Os tratamentos foram uma testemunha capinada e sulfentrazone $0,60 \mathrm{~kg} \mathrm{ha}^{-1}$ (dose recomendada) e $1,20 \mathrm{~kg} \mathrm{ha}^{-1}$ (dobro da dose), aplicados na forma de Boral 500 SC (solução concentrada contendo $500 \mathrm{~g}$ de sulfentrazone por litro), em préemergência, em uma única época $(30 / 3 / 2000)$, com pulverizador costal, à pressão constante fornecida por $\mathrm{CO}_{2}\left(2,46 \mathrm{kgf} \mathrm{cm}{ }^{-2}\right)$, barra com quatro bicos 110.02 (Teejet XR) e faixa de aplicação de 2,0 m com volume de calda correspondente a $275 \mathrm{~L} \mathrm{ha}^{-1}$. As condições edafoclimáticas (dados médios), no período da aplicação dos tratamentos, $8 \mathrm{~h} 30$ a $9 \mathrm{~h} 35 \mathrm{~min}$, foram temperatura do ar $28{ }^{\circ} \mathrm{C}$, umidade relativa do ar $66 \%$, velocidade média do ar $2,30 \mathrm{~m} \mathrm{~h}^{-1}$ e umidade do solo $12,45 \%(\mathrm{p} / \mathrm{p})$.

A unidade experimental foi constituída por 26 $\mathrm{m}^{2}(5,00 \times 5,20 \mathrm{~m})$, correspondendo a quatro linhas de plantio de cana-de-açúcar, espaçadas em 1,30 m. O delineamento estatístico foi em blocos ao acaso, com cinco repetições. Todas as parcelas foram protegidas por aceiros de contorno, $0,5 \mathrm{~m}$ de profundidade por 0,7 de largura, evitando assim, a contaminação entre elas pelas águas das chuvas.

Para a determinação do comportamento do sulfentrazone, através da sua persistência, a metodologia empregada foi a de bioensaios, utilizando beterraba cv. Early Wonder, selecionada em ensaio prévio como planta-teste.

Em cada época avaliada, foi realizada uma amostragem do solo utilizando trado cilíndrico de aço (15 cm de diâmetro por $10 \mathrm{~cm}$ de altura), de forma casualizada em quatro pontos por parcela em 23 épocas: $0,35,73,96,124,165,194,228,250,291,320$, $357,377,419,448,475,497,536,566,601,625,652$ e 704 dias após os tratamentos (DAT). Foram secas ao ar, peneiradas e armazenadas em freezer a $-15^{\circ} \mathrm{C}$ até a preparação dos bioensaios.

Para a determinação da persistência foi utilizada a metodologia de bioensaios, sendo estes dispostos em um fitotron marca Conviron modelo PVG386, regulado para $20{ }^{\circ} \mathrm{C}, 70-80 \%$ de umidade relativa do ar e fotoperíodo de 16 horas, com intensidade luminosa de 35.400 lúmen $\mathrm{m}^{-2}$ (N $780 \mathrm{ìmol}$ $\left.\mathrm{m}^{-2} \mathrm{~s}^{-1}\right)$. Para cada, amostra foram utilizados três copos plásticos de $300 \mathrm{~mL}$ sem percolação, com $250 \mathrm{~g}$ de solo, sendo semeadas três sementes de beterraba. Os copos foram irrigados diariamente em até $80 \%$ da capacidade de campo. Após a germinação, foi realizado o desbaste, permanecendo duas plantas por copo.

Decorridos 14 dias, as plantas foram cortadas rente ao solo e avaliou-se a sua massa fresca epígea. Os dados foram submetidos à análise da variância e as médias comparadas pelo teste $t$ a $5 \%$ de probabilidade.

\section{RESULTADOS E DISCUSSÃO}

A comparação do crescimento da planta teste entre as diversas épocas amostradas somente foi possível pelo uso do fitotron, pois ao contrário dos ensaios que utilizam a mesma metodologia em casa de vegetação, há padronização das condições de temperatura, umidade de solo, umidade do ar, intensidade luminosa e fotoperíodo. Ressalta-se ainda que a alta intensidade luminosa, 35.400 lúmen $\mathrm{m}^{-2}$, e o fotoperíodo de 16 horas, utilizados nos bioensaios, potencializaram a sensibilidade da planta teste, pois o sulfentrazone tem o seu modo de ação ativado pela da luz.

Os resultados dos bioensaios, em massa fresca epígea (g) da beterraba, em função das épocas de avaliação e das doses testadas do sulfentrazone, estão relacionados na figura 1.

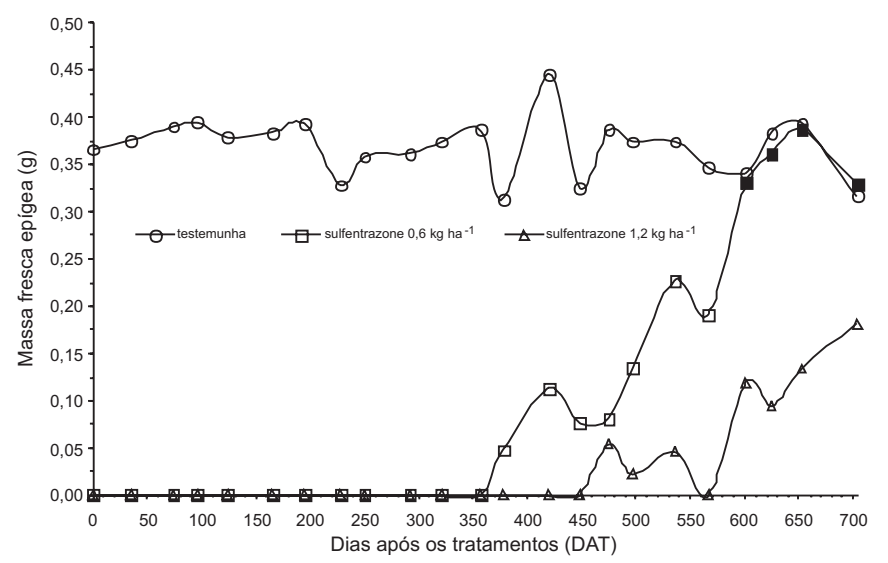

Figura 1. Variação temporal da massa fresca epígea em função dos dias após os tratamentos. representa diferença não significativa $(p>0,05)$ em relação à testemunha. Cada símbolo representa o valor médio de 5 repetições.

Na expressão da fitotoxicidade, avaliada pela massa fresca epígea, somente começou a se notar valores diferentes de zero, expressando assim algum desenvolvimento da planta-teste, aos 377 DAT e 475 DAT, para os respectivos tratamentos, 0,6 e 1,2 kg ha ${ }^{1}$, havendo aumento gradativo da massa até o fim das amostragens, aos 704 DAT.

Observa-se que as doses do sulfentrazone tiveram comportamento diferenciado, em função da dose avaliada. Com a dose de $0,6 \mathrm{~kg} \mathrm{ha}^{-1}$ houve aumento gradativo da massa fresca epígea, embora pelo teste $t$, não tenha diferido da testemunha desde 601 DAT até o fim das amostragens aos 704 DAT. Com a dose de $1,2 \mathrm{~kg} \mathrm{ha}^{-1}$, as médias da massa fresca epígea também foram crescentes e diferiram significativamente da testemunha, mesmo no fim das amostragens. 
Por meio destes valores, pode-se determinar o limite final da persistência do herbicida, na dose de $0,6 \mathrm{~kg} \mathrm{ha}^{-1}$, em $601 \mathrm{DAT}$, enquanto na maior dose foi verificado esta persistência se estendendo por mais 103 dias, sinalizando que a persistência do sulfentrazone quando aplicado na dose de $1,2 \mathrm{~kg}$ ha 1, poderá ultrapassar 704 DAT.

As condições climáticas no período do ensaio estão representadas na figura 2. Observa-se que o regime hídrico durante o período da realização do ensaio foi normal para a região, caracterizado por alternância entre duas condições climáticas distintas, uma com temperaturas médias mais altas e regime hídrico com precipitações pluviais mais abundantes e frequentes, e outra, de forma inversa, temperaturas médias mais baixas e com menor frequência e volume de chuvas, características típicas de estiagem.

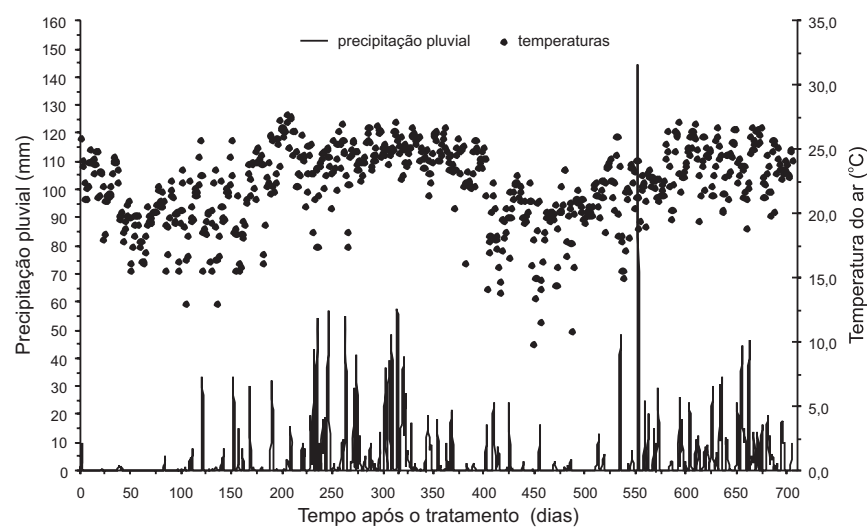

Figura 2. Precipitação pluvial diária e temperatura média do ar, no período de 30/3/2000 a 4/3/2002.

A partir do índice $\mathrm{pH}$ do solo $(6,4)$ e do valor pK do sulfentrazone $(6,56)$, calcula-se $\left(\frac{100}{1 \text { anti } \log (p K p H)}\right)$, em 40,89 a porcentagem das suas moléculas que estariam na forma ionizada; desta forma, a maioria $(59,11 \%)$, estaria na forma molecular, mais suscetível aos processos de sorção aos colóides do solo.

A época da aplicação do herbicida foi no início do outono, caracterizada pela diminuição gradativa das chuvas e do teor de água no solo, o que beneficiou a sorção do herbicida aos colóides do solo e desfavoreceu o desenvolvimento da comunidade microbiana edáfica, participante dos processos de dissipação dos herbicidas (Alexander 1965; Weber 1970). Desta forma, com o herbicida sorvido aos colóides e o crescimento da comunidade microbiana prejudicado, as condições para dissipação e redução da concentração do herbicida no solo não foram as ideais (BRIGGS, 1981; 1984), o que explicaria a falta de desenvolvimento da planta-teste nas primeiras avaliações, o que ocorreu somente a partir de 150
DAT, com o início das chuvas e o aumento das temperaturas médias, perdurando até 450 DAT. Esta nova condição favoreceu o desenvolvimento da comunidade microbiana e a desorção do herbicida aos colóides, disponibilizando-o assim, para os processos dissipativos (Blanco, 1979; WalKer e Allen, 1984; REDDY e LOCKE, 1998), reduzindo a sua concentração no solo e, consequentemente, permitindo o inicio das primeiras germinações da planta-teste, aos 377 e 475 DAT, para os tratamentos 0,6 e $1,2 \mathrm{~kg} \mathrm{ha}^{-1}$ respectivamente (Figura 1 ).

Entretanto, o aumento de temperatura e da precipitação pluvial foi suficiente apenas para que o herbicida fosse dissipado parcialmente, pois após o período de estiagem (448 a $556 \mathrm{DAT}$ ), foi necessário ainda mais uma época de chuvas (550 até 704 DAT), para que houvesse maior dissipação do herbicida e redução progressiva da sua concentração no solo, notoriamente para a dose de $0,6 \mathrm{~kg} \mathrm{ha}^{-1}$.

Na maior dose $\left(1,2 \mathrm{~kg} \mathrm{ha}^{-1}\right)$, observou-se que foram necessários dois períodos com maior precipitação pluvial e temperaturas mais elevadas, para favorecer os processos dissipativos. Embora a planta-teste tenha desenvolvimento com massa fresca epígea crescente, maior que $0,05 \mathrm{~g}$, não foi possível determinar o fim da persistência ao término das avaliações, em 704 DAT. O baixo teor de matéria orgânica $\left(11 \mathrm{~g} \mathrm{dm}^{-3}\right)$ pode ter influenciado na dissipação do herbicida, pois segundo Alexander (1965), o baixo teor não favorece o desenvolvimento da comunidade microbiana, e por consequência, sua dissipação.

Os mecanismos que governam a sorção e a dessorção das moléculas dos herbicidas aos colóides do solo constituem um processo dinâmico. Quando são realizados bioensaios, estes são colocados em uma condição ótima para a dessorção, notoriamente quando a capacidade de campo é mantida a $80 \%$, favorecendo assim a permanência do herbicida na solução do solo, podendo agir sobre a planta-teste. Embora Vivian et al. (2006) qualifiquem o sulfentrazone como de lenta dessorção dos colóides para a solução do solo, observa-se pelos resultados aqui apresentados, que o período de quatorze dias da execução dos bioensaios, mesmo para aquelas amostragens realizadas em pleno período de estiagem, foi suficiente para que houvesse dessorção do herbicida para a solução do solo, absorção pela planta e redução da sua massa epígea, expressando a presença do herbicida.

Blanco e Velini (2005) determinaram a persistência do sulfentrazone em 376 DAT em Latossolo Vermelho Escuro eutrófico. Embora a metodologia, as condições climáticas e a dose $(0,6$ $\mathrm{kg} \mathrm{ha}^{-1}$ ) fossem semelhantes às do presente ensaio, 
as diferenças no teor de matéria orgânica $\left(40 \mathrm{~g} \mathrm{dm}^{-}\right.$ ${ }^{3}$ ), manejo (plantio de culturas em sucessão) e da época de aplicação (verão), colaboraram para as desigualdades entre os valores da persistência, porém, em ambos os ensaios, o herbicida sulfentrazone se caracterizou pela grande persistência no solo.

Evidenciar esta particularidade do sulfentrazone é importante tanto do ponto de vista ecotoxicológico, pois o qualifica como um herbicida que permanece muito tempo no solo, passível a concatenar processos de contaminação ambiental, quanto pelo agronômico, permitindo fazer inferências sobre a época em que se deve realizar o plantio de culturas em sucessão, evitando-se assim o risco de fitotoxicidade para estas culturas, além dos aspectos relacionados à reaplicação do herbicida em cana soca. Neste caso, a provável presença do herbicida no solo, em nova aplicação na cana soca, poderá acarretar concentração do sulfentrazone no solo maior que a indicação agronômica, o que não é desejável.

\section{CONCLUSÃO}

A persistência do herbicida sulfentrazone no solo é longa e proporcional à dose aplicada.

\section{AGRADECIMENTOS}

À FAPESP por financiar esta pesquisa, integrante do projeto temático ${ }^{\circ}$ 1999/08585-9 "Avaliação e controle de pragas, doenças e persistência de herbicidas em agroecossistemas de cana-de-açúcar com sistema de colheita mecanizada, sem queima" coordenado pelo Dr. Antonio Batista Filho; aos Engenheiros Agrônomos Maria de Lourdes Fustaino e Luis Eduardo Corrêa da FMC do Brasil pelo apoio técnico, e ao Engenheiro Glen McDonald, da CONVIRON pelo auxílio na manutenção do Fitotron.

\section{REFERÊNCIAS}

ALEXANDER, M. Persistence and biological reaction of pesticides in soil. Soil Science. American Proccedings, v.29, p.1-7, 1965.

BLANCO, F.M.G.; VELINI, E.D. Persistência do herbicida sulfentrazone em solo cultivado com soja e seu efeito em culturas sucedâneas. Planta Daninha, v.23, p.693-700, 2005.

BLANCO, H.G. Destino, comportamento e resíduos de herbicidas no solo. O Biológico, v. 45, p.225-48, 1979.
BRIGGS, G.G. Factors affecting the uptake of soil-applied chemicals by plants and other organisms. In: SYMPOSIUM ON SOIL AND CROP PROTECTION CHEMICALS, Proceedings... 1984, p.35-47.

BRIGGS, G.G. Theoretical and experimental relationships between soil adsorption, octanol-water partition coefficients, water solubilities, bioconcentration factors, and the parachor. Journal of Agricultural and Food Chemistry, v.29, p.10501059, 1981.

GREY, T.L.; WALKER, R. H.; WEHTJE, G. R.; HANCOCK, H. G. Sulfentrazone adsortion and mobility as affected by soil and pH. Weed Science, v.45, p.733-38, 1997

HESS, D.F. Herbicide effects on plant structure, physiology, and biochemistry. In: ALTMAN, J. (Ed.) Pesticide Interactions in Crop Production. London: CRC Press 1993 p. 13-34.

REDDY, K.N.; LOCKE, M.A. Sulfentrazone sorption, and mineralization in soil from two tillage systems. Weed Science, v. 46, p. 494-500, 1998.

RODRIGUES, N.B.; ALMEIDA, F.S. Guia de herbicidas. 5.ed. Londrina, 2005. 592 p.

ROSSI, C.V.S.; ALVES, P.L.C.A.; MARQUES JUNIOR, J. Mobilidade do sulfentrazone em nitossolo vermelho e em neossolo quartzarênico. Planta Daninha, v.21, p.111-120, 2003.

TOMLIN, C. Pesticide Manual. 10. ed. Cambridge: British Crop Protection Council and The Royal Society of Chemistry, 1994. $1341 \mathrm{p}$.

VIVIAN, R.; REIS, M.R.; JAKELAITIS, A.; SILVA, A.F.; GUIMARÃES, A.A.;SANTOS, J.B.;SILVA, A.A. Planta Daninha, v. 24, p. 741-750, 2006.

WALKER A. e ALLEN, J.G. Influence of soil and environmental factors on pesticide. Soil and Crop Protection Chemistry., v.27, p.27, 1984 .

WEBER, J.B. Mechanism of adsorption of s-triazines by clay colloids and factors affecting plant availability. In: GUNTHER, F.A. (Ed.) Residue Reviews., v.32, p.93-130, 1970. 